\title{
The Application of Salutogenesis to Organisations
}

\author{
Georg F. Bauer and Gregor J. Jenny
}

\section{Framing the Chapter}

This chapter on salutogenic organisations is part of the book section on the application of salutogenesis to everyday settings. The settings covered in this section include communities/neighbourhoods, cities, restorative environments, schools, universities, worksites and prisons. Such settings are broadly defined as 'the place or social context in which people engage in daily activities in which environmental, organisational, and personal factors interact to affect health and wellbeing' (WHO, 1998; emphasis added). This definition implies that all settings are influenced by some form of organisation. Several of the listed settings are more or less formalised organisations themselves, such as worksites, schools, universities and prisons-whereas others are at least heavily influenced by organisations, such as cities, neighbourhoods or restorative environments. Thus, understanding how organisations influence whole settings and human health is crucial for promoting health in and through settings.

As the other chapters on everyday settings illustrate, organisations directly influence the health of their employees through working conditions. They influence the health of their customers through their products or services, such as providing education, and finally, they influence the population's health through larger ecological impacts. In treating these health-influencing pathways, the other chapters either refer to the more general concept of settings or focus on specific aspects of organisations such as the employee, customer (student), citizen, political or ecological level. This chapter presents a generic model of how

\footnotetext{
G.F. Bauer $(\bowtie) \bullet$ G.J. Jenny

Division of Public and Organizational Health, Epidemiology, Biostatistics and Prevention Institute, University of Zürich,

Hirschengraben 84, Zürich CH-8001, Switzerland

e-mail: georg.bauer@uzh.chhttp://www.ebpi.uzh.ch; gregor.

jenny@uzh.chhttp://www.ebpi.uzh.ch
}

organisations influence health from both a salutogenic and pathogenic perspective. The framework integrates concepts and empirical findings from health promotion, organisational psychology and the management sciences. The chapter will focus on the organisation's impact on employee health, as employees typically are most directly and intensely affected by an organisation. Thus, it complements the chapter on salutogenic work by expanding the level of analysis to include the question of how employee health is created by the interaction of employees with key characteristics of the organisation.

Furthermore, we expect that organisations considering employee health a legitimate, relevant focus of attention and action beyond pure economic profitability will also consider their larger health impact on their environment, including customers and the population at large. Finally, the chapter aims to be particularly applicable to for-profit organisations in which it is exceptionally challenging to introduce a health agenda.

The chapter firstly introduces the key concept of organisational health development (OHD), as well as the OHD practical and research context, such as ongoing changes of the economy, of organising work and of the roles of managers and employees. Secondly, the chapter presents conceptual and empirical research regarding OHD as well as health-oriented interventions in organisations that at least partly follow the salutogenic orientation. Finally, conclusions are drawn concerning future salutogenic practice and research in organisations.

\section{Key Concepts and Cultural, Practice and Research Contexts}

The present chapter relates to the EUHPID Health Development Model (Fig. 21.1; Bauer, Davies, \& Pelikan, 2006) as the underlying concept of individual health development. This model states that health is continuously developed 


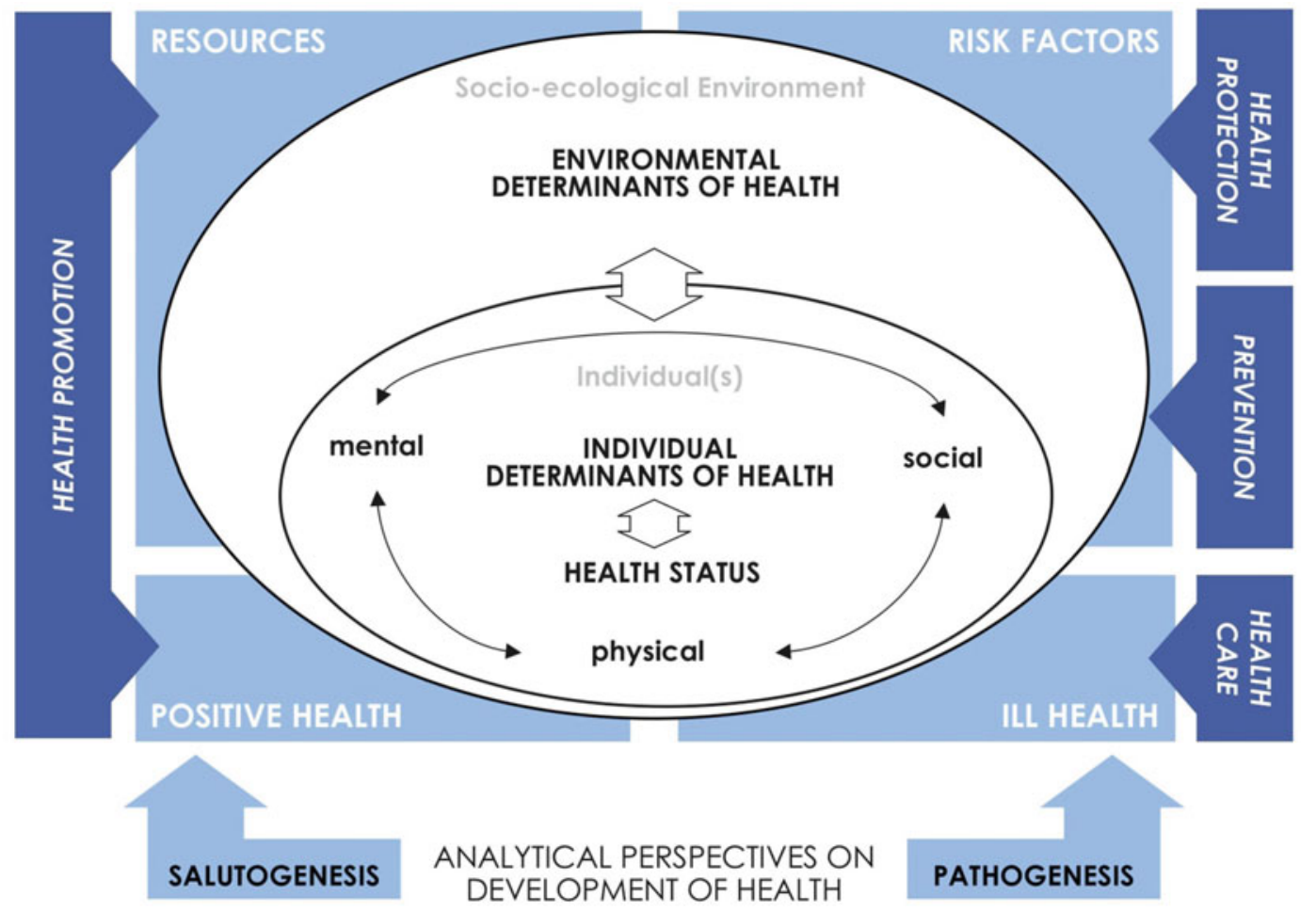

Fig. 21.1 EUHPID health development model (Bauer et al., 2006)

through the interaction between individuals, their individual health determinants and their relevant living environments. This interaction can be characterised from a pathogenic perspective (risk factors $<->$ ill health) and a salutogenic perspective (resources $<->$ positive health). Following this model, organisations can be considered a key living environment and thus a significant contributor to both pathogenic and salutogenic health development. Accordingly, the chapter on salutogenic work showed that working activities can be split into both pathogenic and salutogenic (health development) processes resulting from interactions between employees and the respective organisation they work for.

Building on this conceptualisation, we previously defined organisational health development $(O H D)$ as follows (Bauer \& Jenny, 2012, p. 135):

Organisational health development $(O H D)$ is both the ongoing reproduction and the targeted improvement of health in organisations as social systems, based on the interaction (process dimensions) of individual and organisational capacities (structural dimensions).

In short, ongoing OHD relates to all processes within the organisation that have a salutogenic or pathogenic impact on individual health, whereas targeted OHD relates to optimisation processes that are aimed at improving the ongoing reproduction of individual health (Jenny \& Bauer, 2013). According to this line of thinking, a healthy organisation can be defined as follows:
A healthy organisation is an organisation that is low in producing pathogenic processes, but high in producing salutogenic processes.

In relation to the salutogenic model, a healthy organisation provides an environment that fosters job resources-which can be viewed as general resistance resources - that lead to coherent work experiences, a general sense of coherence and positive health (see the JD-R HealthSoC Model in the chapter on salutogenic work). Similarly, it keeps job demands-or stressors-within an acceptable range and as such reduces the risk of ill health in its employees.

Beyond this human health-centred notion of a healthy organisation, the above definition of a healthy organisation can also be applied to the level of the organisation as a complex social system itself. In this case, producing low pathogenic processes would mean that an organisation is low in organisational-level dysfunctioning, whereas high salutogenic processes would imply that an organisation vitally pursues its organisational purpose.

\section{Societal and Cultural Context}

In most contemporary societies, we live and work in highly organised contexts. Throughout our lives, we encounter many different organisations as students, employees, 
volunteers, customers or persons exposed to mostly damaging ecological changes created by organisations. Thus, the salutogenic quality of these encounters with organisations becomes an ever more important determinant of population health.

On a societal level, research shows that during working age a large proportion of inequalities in health can be explained by inequalities in working conditions. At the same time, less educated people in lower job positions have limited opportunities to change the job if it is detrimental to their health. Organisations become increasingly globally connected, are under constant economic pressure of global competition and need to continuously adapt to a changing economic environment. This implies that organisations as a relevant working environment become less stable, pushing employees to change jobs, employers or even professions. This leads to weaker psychological contracts and less job security-the latter being a key resource for sense of coherence, according to Antonovsky. This demand for the continuous flexibility of employees is intensified by information technology, which allows additional flexibility of working hours and working placesimplying increasing demands for continuous adaptations to new situations.

Not only Western countries have experienced job tasks and thus job characteristics shifting from primarily physical to psychosocial work processes. This implies new forms of 'exposures'. At the same time, physical health and work ability are not sufficient perquisites to fulfil such jobs. Instead, in a knowledge and service-oriented economy, organisations expect their employees to display comprehensive biopsychosocial workability, active work engagement and positive interactions with customers.

These societal and organisational changes meet a changing work force: increasingly well-educated employees demand more and more autonomy, self-defined flexibility, self-fulfilment, opportunities for personal development and a good life domain balance. If these requirements are met, employees are more likely to remain in the job until retirement age - an urgent need in the face of an aging society.

\section{Practice and Research Context}

As the two sections of the present book on salutogenesis' application to everyday and healthcare settings show, international health-promotion networks following a wholesystems approach have been mostly created for professional organisations providing public services-including healthpromoting schools, universities, prisons, cities and hospitals.

In for-profit organisations, health issues are addressed in more limited ways by legally required minimum standards for occupational safety and health and via worksite health- promotion networks largely focusing on traditional lifestylerelated health issues or focusing on the double aim of workers' individual-level health and productivity. Although approaches such as the NIOSH 'total worker health' or the WHO healthy workplace model (WHO, 2010) aim to promote more integrative, comprehensive OHD approaches, their dissemination is limited because they face fragmented structures of organisations with diverse stakeholders and specialists such as safety specialists, ergonomists, occupational physicians, case managers, occupational psychologists, human resource managers and internal organisational developers-as well as traditional top-down power structures challenging participatory, empowering, employee-centred health-promotion approaches (Bauer \& Hämmig, 2014).

At the same time, the societal context described above implies that the stable boundary conditions needed for such static, legally required occupational health and safety systems and for more comprehensive approaches to workers' health are slowly disappearing. One reaction to such unstable organisational environments is that organisations increasingly offer interventions addressing health-related competences and the self-responsibility of individual employees—which meet employees' increasing demand for self-determination at work.

As a complementary strategy, it seems promising to build capacities of organisations as a whole for the continuous self-observation and self-improvement of their health impact on employees. This approach is at the core of the present chapter and is expected to work well in unstable organisations with continuously changing workforce compositions.

From a research perspective, such capacity-building approaches first require a good understanding of the ongoing OHD processes in organisations and what organisations already do for targeted improvements. Related research requires a generic model of OHD to structure the collection of relevant data. In addition, such a model should structure the analysis of complex change processes induced by capacity-building interventions in organisations.

\section{Research}

\section{Organisational Health Research Explicitly Related to Salutogenesis}

Research on salutogenic health development in organisations has been focusing on the relationships between employee-level working conditions and sense of coherence in employees. This research is summarised in the chapter on salutogenic work and in the chapter on sense of coherence in this volume. In contrast, little conceptual and empirical 
research has examined broader, organisational-level factors in the context of salutogenesis. Some research at least addresses specific aspects of organisations in relation to salutogenesis or selected elements of the salutogenic model in relation to organisations.

Antonovsky himself assumed that the type of an organisation influences the degree of recognition an employee receives and the meaningfulness of his/her job (Antonovsky, 1987a). Feldt, Kinnunen, and Mauno (2000) showed that a good organisational climate and working for an organisation providing job security were strongly correlated with a high SoC, which in turn was associated with wellbeing. Two studies found correlations between various leadership dimensions (e.g. organisational climate, supervisory support and teamwork), cultural beliefs and sense of coherence (Cilliers \& Kossuth, 2002; Kossuth \& Cilliers, 2002). Graeser (2011) developed an organisation-based sense of coherence scale 'to identify potential salutogenic factors of a university as an organization and work place'. Building on Antonovsky's development of a family sense of coherence (Antonovsky \& Sourani, 1988), she proposed a setting- or group-based sense of coherence conceptualised as the 'interaction and transaction between the individual and the setting (e.g. family, community, organization, school, university, workplaces, etc.)' (Graeser, 2011, p. 509). Following the dimensions of the general sense of coherence, the university sense of coherence scale assesses how far a university as a whole is perceived as comprehensible, manageable and meaningful. Cross-sectional analyses showed significant correlations with various disease symptoms in two university samples (Graeser, 2011).

\section{Broader Research on Organisational Health}

Beyond this explicit salutogenic perspective, there exists much research on occupational and organisational health that considers organisational-level determinants of health. During recent decades, this research has increasingly shifted away from a pathogenic focus on stressors, stress, disorders and dysfunctioning. Following a general trend towards positive psychology (Seligman \& Csikszentmihalyi, 2000), joband organisational-level resources and positive (health) outcomes are considered. Such literature includes publications on positive occupational health psychology focusing on the employee level, positive organisational behaviour linking individual, short-term, state-like outcomes to organisational factors and positive organisational scholarship emphasising organisational, longer-term outcomes (Bakker \& Derks, 2010; Bakker \& Schaufeli, 2008;
Cameron, Dutton, \& Quinn, 2003; Day \& Randell, 2014; Gilbert \& Kelloway, 2014; Luthans \& Church, 2002; Nelson \& Cooper, 2008).

This positive perspective has been considered to be part of a larger movement towards positive aspects including fields like positive psychology, community psychology, organisational development, appreciative inquiry, pro-social and citizenship behaviour as well as corporate social responsibility as 'other traditions with a focus on positive phenomena' (Cameron et al., 2003, p. 7). This list also exemplifies that the positive turn is accompanied by a trend to look beyond individual-level health resources by including a broad range of social and organisational determinants of health (see also Bennett, Cook, \& Pelletier, 2002; Hofmann \& Tetrick, 2003). Interestingly, this shift corresponds to Antonovsky's much earlier $(1979,1979,1987 b)$ concern to look beyond individual risk factors by addressing overarching general resistance resources on any level, from the individual to the society at large.

In the search for a comprehensive model covering both pathogenic and salutogenic health development processes within the organisational context, we previously conducted a broad review of the conceptual literature covering the field of organisational health (development) (Bauer \& Jenny, 2012). We had structured this review into three aspects that are summarised here.

\section{Organisational Health 'Outcomes'}

Based on 16 different earlier definitions of organisational health, Hofmann and Tetrick (2003) developed a twodimensional integrative framework, distinguishing shortvs. long-term health outcomes, as well as intrinsic vs. extrinsic health goals. Referring to the literature of positive organisational behaviour and scholarship, Quick, Macik-Frey, and Cooper (2007) introduce three superordinate categories of organisational health: leading a life of purpose, quality connections to others, positive self-regard and mastery. Based on this human-based conceptualisation, they suggest that an organisation itself can contribute to broader societal goals than pure effectiveness and economic performance. Similarly, sustainability (Hofmann \& Tetrick, 2003) or corporate social responsibility (Zwetsloot, Leka, \& Jain, 2008) are suggested as broader organisational health outcomes. Jaffe (1995) proposes that a company can be healthy for its own livelihood, its stockholders, employees, suppliers, customers, the community and its ecological environment. 


\section{Organisational Health 'Determinants'}

On-the-job role clarification, balance between job demands and resources, social relationships and support as well as dealing with change have been identified as key determinants of individual (Bond, Flaxman, \& Loivette, 2006) and organisational health (Kerr, McHugh, \& McCrory, 2009). Hart and Cooper (2001) as well as Cotton and Hart (2003) identify the organisational climate to be defined as 'leadership and managerial practices, as well as the organisational structure and processes...' (Cotton \& Hart, 2003, p. 122) as key determinants of OHD. Others propose positive leadership (Luthans \& Church, 2002; Peiró \& Rodríguez, 2008; Quick et al., 2007) or positive organisational culture and climate (Shoaf, Genaidy, Karwowski, \& Huang, 2004) as key factors. The integrative AMIGO model (Peiró, 2000; Peiró \& Rodríguez, 2008) distinguishes hard (e.g. structure and technology) and soft facets of the organisation (e.g. climate and management) as well as core elements (e.g. mission, strategy and culture). The NHS (2009) review suggests interrelation, identity, autonomy and resilience as key components of organisational health (see also the Psychologically Healthy Workplace framework, Kelloway \& Day, 2005).

\section{Relationships and Balance in Organisational Health: Organisations as Social Systems}

Several authors move beyond a linear determinant-outcome logic by considering organisations social, interactive systems (Bennett et al., 2002; DeJoy \& Wilson, 2003; Grawitch, Gottschalk, \& Munz, 2006; NHS, 2009; Peiró \& Rodríguez, 2008) where interactions, reciprocal relationships and self-referential downward and upward spirals (Fredrickson, 2003; Fredrickson \& Dutton, 2008) are key for organisational health. Grawitch et al. (2006) propose the 'Practices for the Achievement of Total Health (PATH)' model. This triangular model summarises the commonplace idea in the organisational health literature (cf. Hart \& Cooper, 2001) that organisational health interventions simultaneously lead to both employee well-being and organisational improvement and that these two outcomes also reinforce each other (see also the HERO model, Salanova, Llorens, Cifre, \& Martinez, 2012). Besides this idea of harmonious mutual benefits or win-win situations between individual-level and organisational-level health, several authors acknowledge possible tensions between intrinsic (employee-oriented) and extrinsic (companyoriented or societal) health-related interests. Hofmann and Tetrick (2003) propose the joint optimisation of competing goals by applying a balanced scorecard (Kaplan \& Norton,
1996) as a 'strategic-level model for organisational health' (p. 18).

In regard to a salutogenic perspective on organisational health, the review showed two models implicitly incorporating both pathogenesis and salutogenesis: Both the organisational health framework (Cotton \& Hart, 2003; Hart \& Cooper, 2001) and the job-demands/resource model (Bakker \& Demerouti, 2007; Demerouti, Bakker, Nachreiner, \& Schaufeli, 2001) distinguish two parallel axes of health development in organisations compatible with the general health development model: demands leading to strain/distress and resources leading to motivation/ morale. Both models also assume cross-cutting relationships, as resources can buffer the demand-strain relationship, whereas demands can impede the positive impact of resources on motivation. The models agree that these relationships are influenced by personal and organisational factors and that the two parallel axes co-produce (organisational) performance as an outcome important to organisations. The organisational health framework explicitly depicts personal and organisational resources in the model itself and introduces reciprocal relationships to government, shareholders, customers and partners as relevant stakeholders in the organisational environment. Compared to the general health development model (Bauer et al., 2006), both these models emphasise mental health over physical and social health. In addition, as descriptive models, they do not cover self-improvement processes and entry points for interventions.

\section{The Organisational Health Development (OHD) Model}

In order to add the management perspective to OHD, we completed the above review on organisational health (Bauer \& Jenny, 2012) with a review of the literature on generic models of organisations, organisational change and management systems (Jenny \& Bauer, 2013). This resulted in the OHD model (Fig. 21.1), which integrates the generic health development model introduced above (Bauer et al., 2006) with the new management model of St. Gallen (RüeggStürm, 2003). The latter combines structuration theory (Giddens, 1984), a systemic viewpoint (Luhmann, 1984) and organisational ethics (Maak \& Ulrich, 2007). The OHD model (Fig. 21.2) shows how organisational capacities (structure, strategy and culture) interact with individual capacities (competence, motivation and identity). This interaction is composed of factual, task-related processes (business, management and supporting) and social, peoplerelated processes (leadership, relations and discourse) between managers, employees and customers. 
Fig. 21.2 Organisational health development (OHD) model (Bauer \& Jenny, 2012; Jenny \& Bauer, 2013)

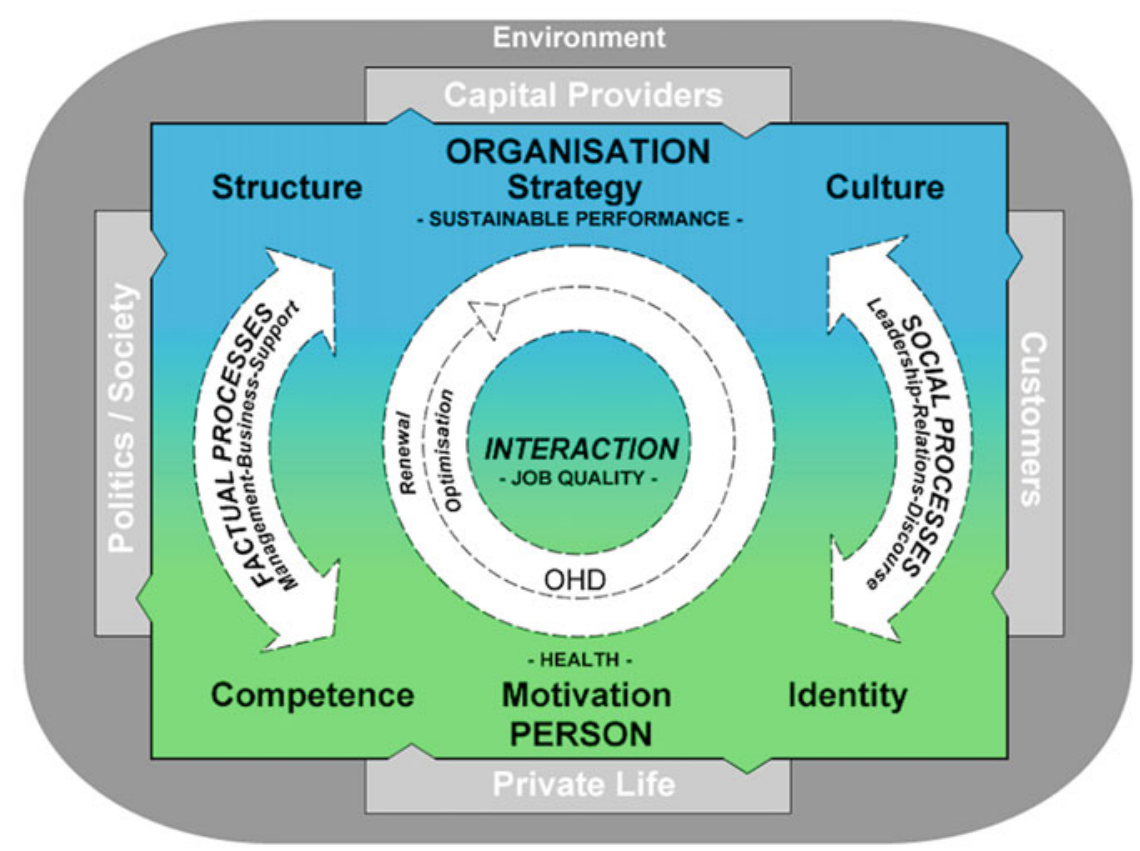

The model assumes that these processes are influenced by and simultaneously shape individual and organisational capacities-comparable to the reciprocal relationship between a river and its riverbed. The thick black line around the organisation symbolises the system's self-referentiality, that is the self-defined borders as well as the language and mental models represented within and guiding the organisation (Jenny \& Bauer, 2013). The model highlights customers, society, financers and the private lives of its members as health-relevant environments of the organisation. Following the logic of a balanced scorecard, the interests of the stakeholders in these environments need to be balanced with the interests of the organisation and of its members.

As an organisation-specific health development model considering organisations to be complex social systems, this model incorporates the following points emerging from the various literature reviews and definitions (Bauer \& Jenny, 2012, pp. 133-134):

- Pre-defined, unidirectional distinctions between determinants and outcomes of OHD are replaced by reciprocal relationships between structural and process dimensions.

- These processes, which reflect multiple interactions between the organisation and its members, are classified into both factual (task-related) and social (people-related) processes.

- Targeted OHD needs to balance tensions between the various structural and process dimensions and between the interests of stakeholders.
- To facilitate the self-optimisation process by organisations, targeted OHD should build on mental models and the language of decision-makers and staff in organisations.

- Both ongoing and targeted OHD is dependent on the organisational environment comprising various stakeholders, from customers to politicians.

The OHD model may provide a common group action theory for both researchers and practitioners in this area, facilitating the development of a well-structured, cumulative evidence base and supporting evidence-based practice. As editors of a recent book on 'salutogenic organisations and change' (Bauer \& Jenny, 2013b), we compared this detailed model to other propositions of OHD of the broad international group of researchers involved in the book. We concluded that a simplified generic OHD framework can mirror the diverse approaches (Fig. 21.3) (Bauer \& Jenny, 2013a).

This framework shows how employees and leaders with their specific roles interact with organisations as a whole and with sub-groups within the organisation. Sub-groups like teams or divisions are considered to be more immediate and thus particularly relevant social environments. Therefore, they provide identity and feasible, meaningful units of change. Again, (factual) work processes are distinguished from social processes. As most researchers in the mentioned volume make a distinction between negative and positive health development processes, this framework splits the work-related and social processes up into health-impairing, pathogenic and health-enhancing, salutogenic processes. 
Fig. 21.3 Generic organisational health framework (Bauer \& Jenny, 2013a)

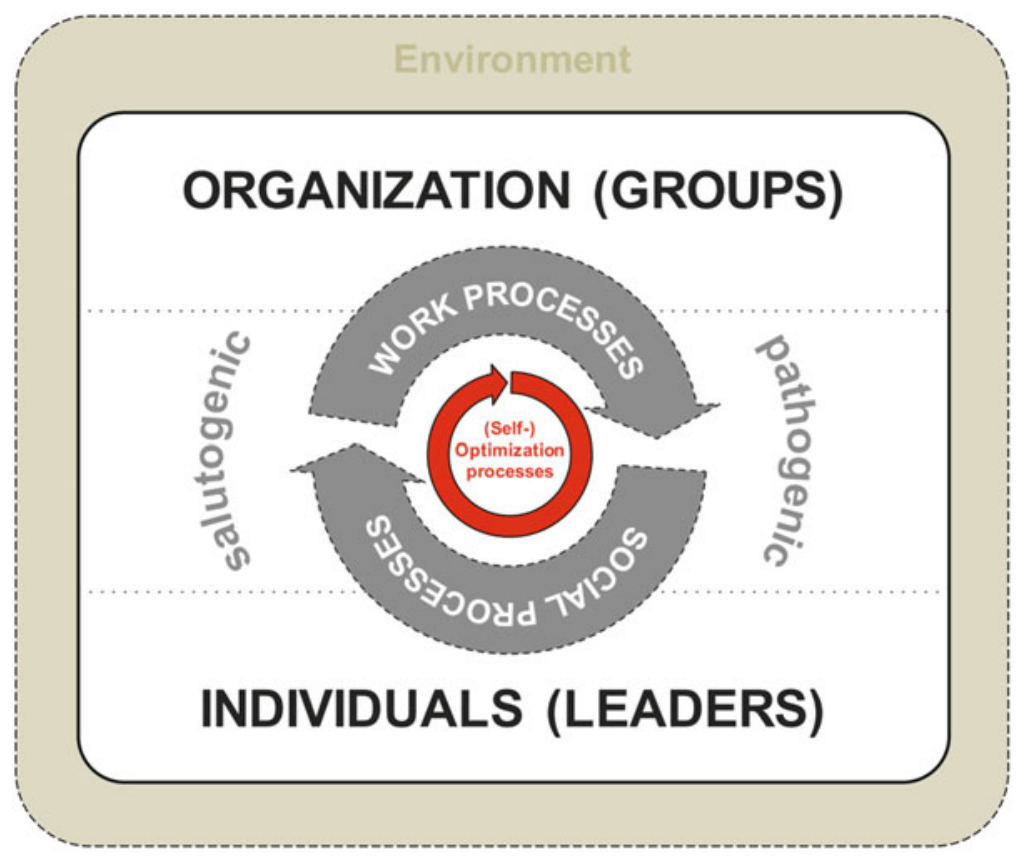

Finally, the framework shows that OHD is influenced by and influences its relevant environment.

\section{Linking Ongoing OHD to the Salutogenic Model}

The organisational health development model permits a well-structured, theory-based application of the salutogenic model to the context of OHD. Firstly, in the context of organisations, individual-level generalized resistance resources are specified as the individual capacities of workrelated competences, motivation and identity. Organisational-level generalized resistance resources can be specified as capacities within the structure, strategy and culture of the organisation. Secondly, these individual- and organisational-level capacities co-produce the factual, taskrelated processes and social processes in an organisation. As shown in detail in the chapter on salutogenic work, these processes can impose job demands or job resources on employees. Referring to the salutogenic model, job demands constitute work-related stressors employees have to cope with, whereas job resources constitute work-related generalized resistance resources.

Further following the salutogenic model, high generalized resistance resources on the individual, work or organisational level, as well as successful activation of the general sense of coherence for coping with high job demands, all contribute to coherent work experiences, which in turn strengthens the general sense of coherence.
The coherent work experience can be either perceived and measured on the individual level, as suggested by the WorkSOC (Vogt, Jenny, \& Bauer, 2013; for details, see the chapter on salutogenic work), or on the collective level, as suggested by Graeser's University-SOC (2011).

\section{Interventions for Improving OHD}

After understanding how health develops within the organisational context on an everyday basis, the question arises how this ongoing health development can be positively influenced by targeted interventions-driven by the organisation itself or by external organisational health specialists. The international literature reveals many practices for improving OHD and groups them into diverse, inductively derived categories (see Bauer \& Jenny, 2012): 'healthy workplace practices' addressing work-life balance, employee growth and development and employee involvement (Grawitch et al., 2006); 'approaches to organizational health' covering individual health promotion, job redesign and autonomous work groups (Shoaf et al., 2004); 'practitioner models' like health and productivity management, healthy culture planning and the healthy company (Bennett et al., 2002); 'leadership development' (Peiró \& Rodríguez, 2008; Quick et al., 2007) or 'self-assessment/adaptability' (Bennett et al., 2002, p. 72).

Previously, we proposed mapping practices for targeted OHD in a pyramid (Fig. 21.4). This pyramid communicates that the further up an OHD practice is depicted, a smaller 


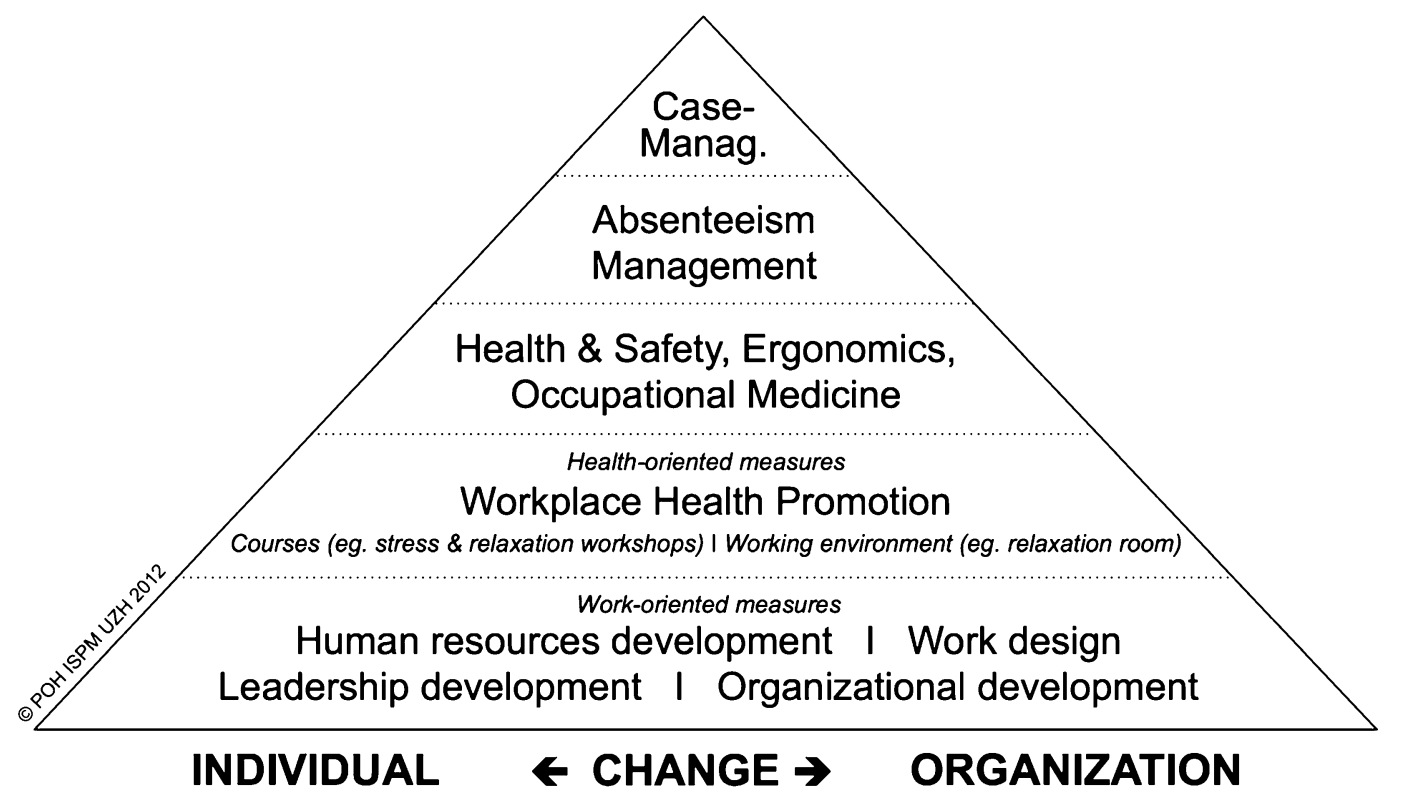

Fig. 21.4 Targeted OHD practices (Bauer et al., 2014)

proportion of employees benefit from it. At the top, only a very few employees with long-term absenteeism benefit from case-management systems to promote re-integration at work. The few employees with repeated events of absenteeism during a certain period of time obtain support from absenteeism programmes, analysing and potentially reducing reasons for repeated absences. Employees at particularly hazardous workplaces benefit from health and safety measures as well as from regular exams by occupational physicians. Worksite health-promotion programmes mostly address lifestyle-related issues at the workplace-but only reach parts of the employees who are interested in such issues. The bottom of the pyramid refers to work-oriented measures aiming to improve the working conditions that affect all employees every day. Furthermore, the pyramid communicates that, for each OHD practice, changes can be induced on the individual or organisational level. This pyramid has shown to be useful to map current practices in organisations and to reflect which level would be most beneficial for future OHD (see Bauer, Lehmann, BlumRüegg, \& Jenny, 2014).

\section{Intervention Approaches: From Fidelity to Figuration}

To better compare diverse intervention approaches to improve OHD, we propose categorising OHD interventions in reference to approaches distinguished in the field of human resource management (see Bauer \& Jenny, 2013a; Delery \& Doty, 1996; Grawitch et al., 2006):
- The universalistic approach: Practices that are effective regardless of the setting to which they are applied

- The contingency approach: The effectiveness of an organisational practice is dependent on its consistency with other organisational components such as structure and strategy

- The configurational approach: The total system of organisational practices needs to be improved to achieve a profound impact

These deductively defined categories distinguish different types of relationships between an intervention and the organisation in which it is implemented. We apply these three approaches to OHD interventions as follows (see Table 21.1):

\section{Universalistic OHD}

The focus of a universalistic OHD intervention is the intervention itself; it aims to assure the fidelity of its own implementation and the reaching of expected outcomes. The intervention context (the organisation) is selected so that the intervention can be implemented with least possible interference. The content of the intervention and the planned implementation process - that is when to implement what intervention element in which way with whom-are predefined and standardised. The research objective is to produce evidence of the static implementation's effectiveness, whereas the change process - as it is (seemingly) predictable - is of minor interest. 
Table 21.1 Intervention characteristics specified for key approaches to OHD interventions (from Bauer \& Jenny, 2013a, with minor adaptations)

\begin{tabular}{|c|c|c|c|}
\hline \multirow[b]{2}{*}{$\begin{array}{l}\text { Intervention } \\
\text { characteristics }^{\mathrm{b}}\end{array}$} & \multicolumn{3}{|c|}{ Organisational health intervention approaches ${ }^{\mathrm{a}}$} \\
\hline & A. Universalistic & B. Contingency & C. Configurational \\
\hline Focus & $\begin{array}{l}\text { Fidelity of the } \\
\text { intervention }\end{array}$ & Fit between intervention and organisation & Figuration of the organisation \\
\hline Content & Predefined & Predefined or modified & Emergent \\
\hline Context & $\begin{array}{l}\text { Relevant for selection and } \\
\text { targeting }\end{array}$ & Relevant for tailoring/fitting & Relevant as co-actor of change \\
\hline $\begin{array}{l}\text { Implementation } \\
\text { process }\end{array}$ & Standardised & Tailored/fitted & Co-created \\
\hline Change process & $\begin{array}{l}\text { Issue-specific } \\
\text { individual + group } \\
\text { learning }\end{array}$ & $\begin{array}{l}\text { Multi-level learning through a } \\
\text { participatory problem-solving cycle }\end{array}$ & $\begin{array}{l}\text { Capacity building for ongoing health } \\
\text { improvements + increased legitimacy of health }\end{array}$ \\
\hline Outcome & Predefined & Predefined or modified & Predefined (health capacities) + emergent \\
\hline Research & $\begin{array}{l}\text { Effect of static } \\
\text { implementation }\end{array}$ & $\begin{array}{l}\text { Process }+ \text { effect of dynamic } \\
\text { implementation }\end{array}$ & $\begin{array}{l}\text { Process }+ \text { effect of interactive capacity-building } \\
\text { process }\end{array}$ \\
\hline
\end{tabular}

${ }^{a}$ Terminology of universalistic, contingency and configurational based on Delery and Doty (1996)

${ }^{\mathrm{b}}$ Terminology based on Fridrich et al. (2015); see also Biron and Karanika-Murray (2015)

\section{Contingency OHD}

The focus of a contingent OHD intervention is the desired fit between a partly predefined intervention and organisations in need of this intervention. The planned implementation process includes tailoring and fitting the intervention content and process to some degree to the context of the specific organisation - in order to increase its acceptance and effectiveness. This is usually done at the project start together with top decision-makers, subsequently with the operative project managers and then during participatory workshops with line managers and employees. This dynamic implementation process needs to be researched accordingly in order to understand under which conditions intervention outcomes can be achieved through multilevel (organisational) learning mechanisms.

\section{Configurational OHD}

The focus of a configurational OHD intervention is the organisational 'figure' itself, that is the system's configuration in terms of individual and organisational capacities that influence its members' health. The organisational context is not a mere boundary condition promoting or hindering the intervention, but the key target and the key actor of change. Thus, the content and process of the intervention will only emerge from this context and be co-created and owned by the organisation itself. As the external change agent increasingly builds the capacity of the organisation for continuous self-improvement, he/she will be less and less involved. Research will focus on this process of capacity building and on its effect on the organisation's ability to go through similar optimisation processes in the future.
A recent compilation of (salutogenic) OHD interventions (Bauer \& Jenny, 2013b) showed that practices following a contingency approach are most prevalent in the field. The one-size-fits-all approach has been widely criticised and largely overcome with adaptive intervention designs applying variations of participatory problem-solving cycles (cf. Henning \& Reeves, 2013; Ipsen \& Andersen, 2013; Nielsen, Stage, Abildgaard, \& Brauer, 2013). These interventions emphasise the need for aligning (von Thiele Schwarz \& Hasson, 2013) or fitting (Randall \& Nielsen, 2012) the intervention to the respective organisation where it is implemented. This approach has even been applied to the employee survey used for initial problem analysis by tailoring it to each organisational context (Nielsen, Abildgaard, \& Daniels, 2014). Such non-standardised interventions generate challenges for their evaluation, as both the process and context need to be thoroughly evaluated to understand under what circumstances the interventions are effective for what sub-groups (see also Karanika-Murray \& Biron, 2013). Although capacity building for future problem solving is not the primary aim of interventions following a contingency approach, evaluations should still assess the degree of capacity building achieved to consider the potential for long-term, sustainable intervention effects.

\section{Targeted Organisational Health Development as Configurational Capacity Building}

Declarations on (workplace) health promotion and health development advocate empowering and sustainable approaches (European Network for Workplace Health Promotion, 1997; WHO, 1986), which can be considered configurational approaches. As shown above, we apply the concept of 'capacity building' as such a configurational 
approach to enhance an organisation's health-oriented selfoptimisation, or in other words, its targeted OHD (see Bauer et al., 2014, and Hoffmann, Jenny, \& Bauer, 2014, for details).

Based on the organisational capacities (structure, strategy and culture) and employees' capacities (competence, motivation and identity) as the organisation's initial configuration, external change agents develop an intervention architecture together with internal project managers. This intervention architecture defines which intervention elements such as surveys or workshops are implemented with whom in which sequential order. The architecture also considers previous experience and routines with (healthoriented) optimisation processes in the organisation. As line managers are seen as key change agents in organisations, they typically take part in a workshop where they learn to see and talk about OHD from their perspective and within the logic of their organisation. They selfexperience how to improve the salutogenic and pathogenic qualities of their own factual and social processes and are empowered to work with their team on these issues. In team workshops following the format of a solution-oriented 'future workshop', line managers and their teams engage in a discussion about reducing their job demands and increasing their job resources. Participants in these workshops create lists of measures that are targeted at the individual, leader, group/team or organisational levels. Finally, in refresher sessions, the implementation progress is monitored, and the participants reflect upon their experiences.

\section{OHD Research Model}

Integral to this capacity-building process is a schematic version of the OHD model (see Fig. 21.5), which was originally developed for research purposes (Bauer \& Jenny, 2012; Jenny et al., 2011, 2014) but has also proven to be more comprehensible to practitioners and organisations. Compared to the OHD model with the reciprocal relationships shown above (Fig. 21.2), it introduces a more linear depiction of the relationships between organisational and individual capacities that jointly produces job demands and job resources, leading to positive/negative health and finally to sustainable performance as intermediary and distal outcomes. Furthermore, it shows at the very left-hand side the more small-scale interventions for optimisation or the more profound interventions for deep renewal as the initial input targeting both the capacities and the job demands/ resources.

During interventions, this model serves as a common mind map and group action theory for all stakeholders, generating a common language, compatible perspectives and mutual action. Moreover, it supports systemic, multilevel thinking, enabling company members to see their blind spots, facilitates the formulation of hypotheses on how the organisation impacts their health and raises awareness about the circularity of and the interaction between the organisation and its individual members. At the beginning of intervention projects, the model is used to sensitise management to the multiple levels of ongoing and targeted OHD.
Fig. 21.5 OHD research model (based on Bauer \& Jenny, 2012)
Organisational ENVIRONMENT

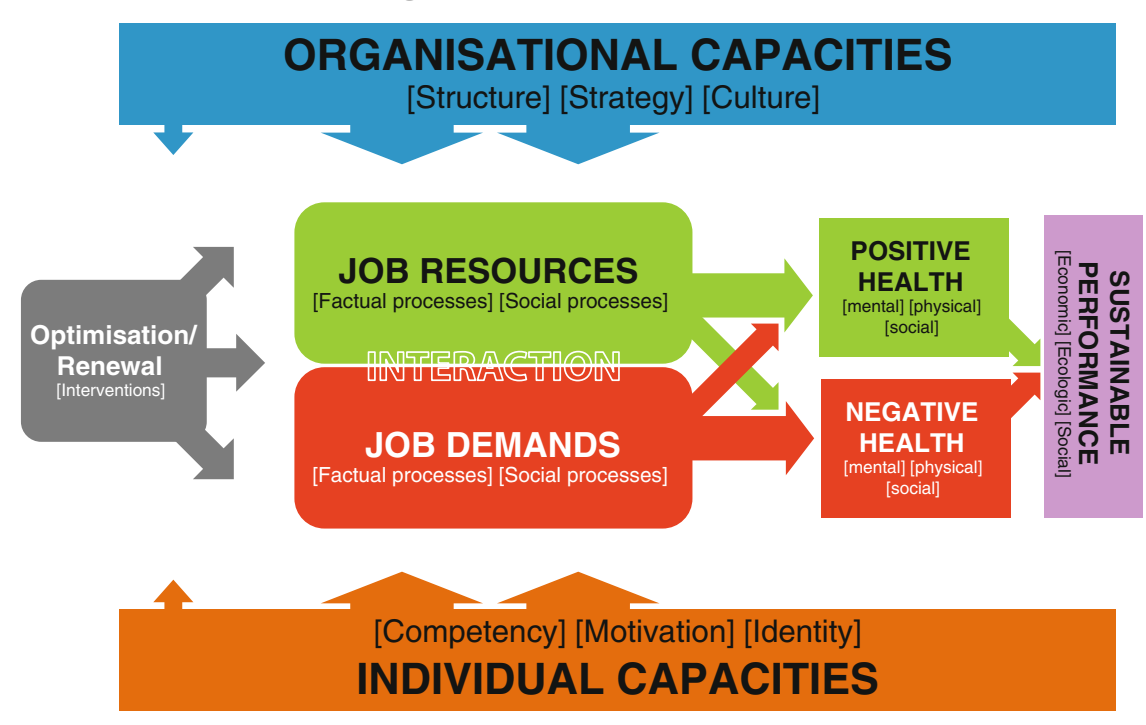

Individual ENVIRONMENT 
During the project, it is used to map developed measures for improving $\mathrm{OHD}$ in regard to their primary target: organisational or individual capacities, or factual (taskrelated) or social processes.

This approach to targeted OHD has been developed in close collaboration with OHD consultants in the field and applied to targeted OHD processes in medium-sized and large companies from the production, healthcare and broader service sectors (See Bauer et al., 2014). In the research context, the model has also been applied as an evaluation framework in a large-scale stress management intervention study to structure and condense data from both quantitative and qualitative sources (Jenny et al., 2014). Hereby, it also figured for the step-wise, causal narration of the final evaluation report (Jenny et al., 2011) and structural equation modelling in regard to the core JD-R-Health model (Brauchli, Jenny, Füllemann, \& Bauer, 2015; see also the chapter on salutogenic work).

\section{Linking Targeted OHD to the Salutogenic Model}

Last not least, the OHD research model can be used to relate interventions for targeted OHD to the model of salutogenesis. As the model shows interventions for optimisation/renewal can either focus on individual or organisational capacities-or capacity-related generalized resistance resources in salutogenic terms. Alternatively, interventions can directly target job demands and job resources as work-related stressors and work-related generalized resistance resources. Both approaches are expected to contribute to a coherent work experience through a better balance between job demands (work-related stressors) and job resources (work-related GRR).

Additionally, the capacity-building approach described above implies increased OHD-related decision making and self-determined actions by employees as key actors of targeted OHD. Antonovsky considered involvement in decision making to be a key source of sense of coherence. In addition, using the OHD model during the intervention as a common frame of reference in the involved organisations increases the likelihood that the intervention itself is perceived as more comprehensible, manageable and meaningful—and thus more coherent by the members of the organisation.

\section{Discussion}

Considering sense of coherence to be the core of the salutogenic model, the design and implementation of interventions for targeted OHD inherently should aim to be perceived as coherent. As shown above, building on a shared mind map of organisational health like the OHD model and participatory approaches involving employees and leaders in improving OHD in their organisation are useful toward this end.

Regarding generalized resistance resources, both individual-level and organisation-level capacities should be built up. These two levels imply a shared responsibility for improving OHD in organisations. However, in practice, this shared responsibility is challenged by an increasingly flexible working society where employees only spend limited time in a single organisation due to flexible work arrangements and repeated changes of employers. Thus, besides enabling organisations to promote the health of a continuously changing workforce, employees need to be enabled to develop individual strategies for improving their work experience. This is exemplified by the numerous individual-level programmes for better coping with or pro-active job crafting of their own work experience.

Furthermore, the salutogenic orientation implies a move beyond disease prevention towards strengthening job resources and the promotion of positive health experiences related to work. This positive focus requires the development of organisation-related indicators of positive health and performance that are attractive to both employees and often economically driven power holders in organisations. Promising ways to obtain the buy-in of organisations might be linking the promotion of positive health to the broader corporate agendas of sustainable workability and the engagement of an aging workforce, of being perceived as an attractive employer as well as the desire to show social responsibility and sustainability.

Specifying the general health development model for the specific living environment of organisations helps to study simultaneously both pathogenic and salutogenic health development processes in this context. Such a model-driven approach allows the classification of generalized resistance resources on the one hand into individual- and organisational-level capacities - that can be assumed to be more stable generalized resistance resources - and on the other hand into factual and social job resources related to work processes-that are expected to be more dynamic generalized resistance resources. This clear classification system allows the systematic study of the relative influence of both types of GRR on work-related sense of coherence, general sense of coherence as well as negative and positive health outcomes.

Regarding intervention research, the classification of interventions into universalistic, contingency and configurational approaches allows the distinguishing of different roles of organisations as the context of interventions and guides to formulate key research questions regarding the intervention characteristics specific to the respective approaches. 
From a salutogenic perspective, it further seems promising to assess the perceived comprehensibility, manageability and meaningfulness of implemented interventions as an immediately salutogenic process indicator. Regarding outcome research, the OHD research model suggests the conducting of a step-wise analysis from changes in job demands and job resources to changes in negative and positive health outcomes, finally leading to changing performance. Moreover, the model suggests the assessment of changes of individual and organisational capacities as indicators of more figurational and thus sustainable changes.

Field research regarding capacity building for targeted OHD in organisations as complex systems will require study designs 'fit for purpose' (Cox, Karanika, Griffiths, \& Houdmont, 2007), for example by retrospectively assigning employees to intervention and control groups based on the analysis of who could be reached by an organisation-wide intervention or based on their assessment of the intervention's impact (Jenny et al., 2014; Randall, Griffiths, \& Cox, 2005). In addition, it could be advisable to focus such intervention research on teams as smaller, more feasible sub-units of analysis and change in organisations (Ipsen, Poulsen, \& Jenny, 2015). In both cases, a mixed-methods approach will allow researchers to systematically collect and analyse the context, process and outcomes of such comprehensive interventions (Biron \& Karanika-Murray, 2014; Fridrich, Jenny, \& Bauer, 2015).

\section{Challenges for the Future}

The greatest challenge ahead will be to reflect upon and redefine the role of organisations in society. Currently, there is a broad consensus that organisations-particularly for-profit corporations - are independent, hardly regulated entities that have the primary purpose of generating profits and that are little accountable to society at large. As societies provide stable environments and pre-conditions for the thriving of organisations, they can demand that organisations directly contribute to the larger aims of society and their members. The concepts of healthy organisations and OHD would require that organisations regularly assess and improve both pathogenic and salutogenic processes for the benefit of their members and their larger environment.

Open Access This chapter is distributed under the terms of the Creative Commons Attribution-Noncommercial 2.5 License (http:// creativecommons.org/licenses/by-nc/2.5/) which permits any noncommercial use, distribution, and reproduction in any medium, provided the original author(s) and source are credited.

The images or other third party material in this chapter are included in the work's Creative Commons license, unless indicated otherwise in the credit line; if such material is not included in the work's Creative Commons license and the respective action is not permitted by statutory regulation, users will need to obtain permission from the license holder to duplicate, adapt or reproduce the material.

\section{References}

Antonovsky, A. (1979). Health, stress, and coping. San Francisco, CA: Jossey-Bass.

Antonovsky, A. (1987a). Health promoting factors at work: The sense of coherence. In C. L. Cooper, R. Kalimo, \& M. El-Batawi (Eds.), Psychosocial factors at work and their relation to health (pp. 153-167). Geneva: WHO.

Antonovsky, A. (1987b). Unraveling the mystery of health: How people manage stress and stay well. San Francisco, CA: Jossey-Bass.

Antonovsky, A., \& Sourani, T. (1988). Family sense of coherence and family adaptation. Journal of Marriage and the Family, 50(Feb), 79. doi: $10.2307 / 352429$.

Bakker, A. B., \& Demerouti, E. (2007). The job demands-resources model: State of the art. Journal of Managerial Psychology, 22(3), 309-328. doi:10.1108/02683940710733115.

Bakker, A. B., \& Derks, D. (2010). Positive occupational health psychology. In S. Leka \& J. Houdmont (Eds.), Occupational health psychology (pp. 194-224). Oxford: Wiley-Blackwell.

Bakker, A. B., \& Schaufeli, W. B. (2008). Positive organizational behavior: Engaged employees in flourishing organizations. Journal of Organizational Behavior, 29(2), 147-154. doi:10.1002/job.515.

Bauer, G. F., Davies, J. K., \& Pelikan, J. (2006). The EUHPID Health Development Model for the classification of public health indicators. Health Promotion International, 21, 153-159.

Bauer, G. F., \& Hämmig, O. (2014). Bridging occupational, organizational and public health: A transdisciplinary approach. In G. F. Bauer \& O. Hämmig (Eds.), Bridging occupational, organizational and public health (pp. 1-11). Dordrecht: Springer.

Bauer, G. F., \& Jenny, G. J. (2012). Moving towards positive organizational health: Challenges and a proposal for a research model of organizational health. In J. Houdmont, S. Leka, \& R. R. Sinclair (Eds.), Contemporary occupational health psychology: Global perspectives on research and practice (pp. 126-145). Chichester: Wiley.

Bauer, G. F., \& Jenny, G. J. (2013a). From fidelity to figuration: Current and emerging approaches to organizational health intervention research. In G. F. Bauer \& G. J. Jenny (Eds.), Salutogenic organizations and change. The concepts behind organizational health intervention research (pp. 1-16). Dordrecht: Springer.

Bauer, G. F., \& Jenny, G. J. (Eds.). (2013b). Salutogenic organizations and change: The concepts behind organizational health intervention research. Dordrecht: Springer.

Bauer, G. F., Lehmann, K., Blum-Rüegg, A., \& Jenny, G. J. (2014). Systemic consulting for organizational health development: Theory and practice. In G. F. Bauer \& O. Hämmig (Eds.), Bridging occupational, organizational and public health (pp. 117-132). Dordrecht: Springer.

Bennett, J. B., Cook, R. F., \& Pelletier, K. R. (2002). Toward an integrated framework for comprehensive organizational wellness: Concepts, practices, and research in workplace health promotion. In L. E. Tetrick (Ed.), Handbook of occupational health psychology. Washington, DC: American Psychological Association.

Biron, C., \& Karanika-Murray, M. (2014). Process evaluation for organizational stress and well-being interventions: Implications for theory, method, and practice. International Journal of Stress Management, 21(1), 85-111. doi:10.1037/a0033227.

Biron, C., \& Karanika-Murray, M. (2015). From black and white to colours: Moving the science of organizational interventions for stress and well-being forward. In M. Karanika-Murray \& C. Biron (Eds.), Derailed organizational interventions for stress and well- 
being (pp. 275-282). Dordrecht, The Netherlands: Springer. doi:10. 1007/978-94-017-9867-9_32.

Bond, F. W., Flaxman, P. E., \& Loivette, S. (2006). A business case for the Management Standards of Stress. HSE Research Report 431. Sudbury, UK: HSE Books.

Brauchli, R., Jenny, G. J., Füllemann, D., \& Bauer, G. F. (2015). Towards a job demands-resources health model: Empirical testing with generalizable indicators of job demands, job resources, and comprehensive health outcomes. BioMed Research International http://dx.doi.org/10.1155/2015/959621

Cameron, K. S., Dutton, J. E., \& Quinn, R. E. (2003). Positive organizational scholarship. San Francisco: Berrett-Koehler.

Cilliers, F., \& Kossuth, S. (2002). The relationship between organisational climate and salutogenic functioning. SA Journal of Industrial Psychology, 28(1), 8-13. doi:10.4102/sajip.v28i1.42.

Cotton, P., \& Hart, P. M. (2003). Occupational wellbeing and performance: A review of organisational health research. Australian Psychologist, 38(2), 118-127. Retrieved from http://www. informaworld.com/10.1080/00050060310001707117.

Cox, T., Karanika, M., Griffiths, A., \& Houdmont, J. (2007). Evaluating organizational-level work stress interventions: Beyond traditional methods. Work \& Stress, 21(4), 348-362. doi:10.1080/ 02678370701760757.

Day, A., \& Randell, K. D. (2014). Building a foundation for psychologically healthy workplaces and well-being. In A. Day, E. K. Kelloway, \& J. J. Hurrell (Eds.), Workplace well-being. How to build psychologically healthy workplaces (pp. 3-26). Chichester: Wiley-Blackwell.

DeJoy, D. M., \& Wilson, M. G. (2003). Organizational health promotion: Broadening the horizon of workplace health promotion. American Journal of Health Promotion, 17(5), 337-341.

Delery, J. E., \& Doty, D. H. (1996). Modes of theorizing in strategic human resource management: Tests of universalistic, contingency, and configurational performance predictions. The Academy of Management Journal, 39(4), 802-835. Retrieved from http://www.jstor. org/stable/256713.

Demerouti, E., Bakker, A. B., Nachreiner, F., \& Schaufeli, W. B. (2001). The job demands-resources model of burnout. Journal of Applied Psychology, 86, 499-512.

European Network for Workplace Health Promotion. (1997). The Luxembourg declaration on workplace health promotion in the European Union. Luxembourg: European Network for Workplace Health Promotion. Retrieved from http://www.enwhp.org/ fileadmin/rs-dokumente/dateien/Luxembourg_Declaration.pdf

Feldt, T., Kinnunen, U., \& Mauno, S. (2000). A mediational model of sense of coherence in the work context: A one-year follow-up study. Journal of Organizational Behavior, 21(4), 461-476. doi:10.1002/( SICI)1099-1379(200006)21:4<461::AID-JOB11>3.0.CO;2-T.

Fredrickson, B. L. (2003). Positive emotions and upward spirals in organizations. In K. Cameron, J. Dutton, \& R. Quinn (Eds.), Positive organizational scholarship (pp. 163-175). San Francisco: Berrett-Koehler.

Fredrickson, B. L., \& Dutton, J. E. (2008). Unpacking positive organizing: Organizations as sites of individual and group flourishing. The Journal of Positive Psychology, 3(1), 1-3. doi:10. 1080/17439760701750964.

Fridrich, A., Jenny, G. J., \& Bauer, G. F. (2015). The context, process, and outcome evaluation model for organisational health interventions. BioMed Research International http://dx.doi.org/10. $1155 / 2015 / 414832$

Giddens, A. (1984). The constitution of society, outline of the theory of structuration. Cambridge: Polity Press.

Gilbert, S., \& Kelloway, E. K. (2014). Positive psychology and the healthy workplace. In A. Day, E. K. Kelloway, \& J. J. Hurrell (Eds.), Workplace well-being. How to build psychologically healthy workplaces (pp. 50-71). Chichester: Wiley-Blackwell.
Graeser, S. (2011). Salutogenic factors for mental health promotion in work settings and organizations. International Review of Psychiatry, 23(6), 508-515. doi:10.3109/09540261.2011.637909.

Grawitch, M. J., Gottschalk, M., \& Munz, D. C. (2006). The path to a healthy workplace: A critical review linking healthy workplace practices, employee well-being, and organizational improvements. Consulting Psychology Journal: Practice and Research, 58(3), 129-147. doi:10.1037/1065-9293.58.3.129.

Hart, P. M., \& Cooper, C. L. (2001). Occupational stress: Toward a more integrated framework. In D. S. N. Anderson \& H. K. S. Ones (Eds.), Handbook of industrial, work and organizational psychology (Vol. 2, pp. 93-114). London, UK: Sage.

Henning, R. A., \& Reeves, D. W. (2013). An integrated health protection/promotion program supporting participatory ergonomics and salutogenic approaches in the design of workplace interventions. In G. F. Bauer \& G. J. Jenny (Eds.), Salutogenic organizations and change (pp. 307-325). Dordrecht, The Netherlands: Springer. doi:10.1007/978-94-007-6470-5_17.

Hoffmann, S., Jenny, G. J., \& Bauer, G. F. (2014). Capacity building as a key mechanism of organizational health development. In G. F. Bauer \& O. Hämmig (Eds.), Bridging occupational, organizational and public health (pp. 103-116). Dordrecht: Springer.

Hofmann, D. A., \& Tetrick, L. E. (2003). The etiology of the concept of health: Implications for 'organizing' individual and organizational health. In L. E. Tetrick (Ed.), Health and safety in organizations: A multilevel perspective (pp. 1-26). San Francisco, CA: Jossey-Bass.

Ipsen, C., \& Andersen, V. (2013). A multi-level and participatory model of prevention of work-related stress in knowledge work. In G. F. Bauer \& G. J. Jenny (Eds.), Salutogenic organizations and change: The concepts behind organizational health intervention research (pp. 127-148). Dordrecht: Springer. doi:10.1007/978-94007-6470-5 8 .

Ipsen, C., Poulsen, S., \& Jenny, G. J. (2015). Editorial: New ideas and insights into designing and understanding effective and sustainable interventions. International Journal of Human Factors and Ergonomics, 3(3/4), 229-234.

Jaffe, D. T. (1995). The healthy company: Research paradigms for personal and organizational health. In S. L. Sauter \& L. R. Murphy (Eds.), Organizational risk factors for job stress (pp. 13-39). Washington, DC: American Psychological Association. doi:10. 1037/10173-001.

Jenny, G. J., \& Bauer, G. F. (2013). The limits of control: A systemic, model-based approach to changing organisations towards better health. In G. F. Bauer \& G. J. Jenny (Eds.), Salutogenic organizations and change: The concepts behind organizational health intervention research (pp. 167-187). Dordrecht: Springer. doi:10.1007/978-94-007-6470-5_10.

Jenny, G. J., Brauchli, R., Inauen, A., Fullemann, D., Fridrich, A., \& Bauer, G. F. (2014). Process and outcome evaluation of an organizational-level stress management intervention in Switzerland. Health Promotion International, 1-13. doi:10.1093/ heapro/dat091

Jenny, G. J., Inauen, A., Brauchli, R., Füllemann, D., Müller, F., \& Bauer, G. F. (2011). Projekt SWiNG-Schlussbericht der Evaluation [Project SWiNG-Final report of the evaluation]. Retrieved from www.gesundheitsfoerderung.ch/swing

Kaplan, R. S., \& Norton, D. P. (1996). Using the balanced scorecard as a strategic management system. Harvard Business Review, 74(1), 75-85. Retrieved from http://search.ebscohost.com/login.aspx? direct $=$ true $\& d b=$ buh $\& A N=9601185348 \&$ site $=$ ehost-live .

Karanika-Murray, M., \& Biron, C. (2013). The nature of change in organizational health interventions: Some observations and propositions. In G. F. Bauer \& G. J. Jenny (Eds.), Salutogenic organizations and change (pp. 239-258). Dordrecht, The Netherlands: Springer. doi:10.1007/978-94-007-6470-5 13. 
Kelloway, E. K., \& Day, A. L. (2005). Building healthy workplaces: What we know so far. Canadian Journal of Behavioral Science, 37, 223-235. doi:10.1037/h0087259.

Kerr, R., McHugh, M., \& McCrory, M. (2009). HSE management standards and stress-related work outcomes. Occupational Medicine, 59(8), 574-579. doi:10.1093/occmed/kqp146.

Kossuth, S. P., \& Cilliers, F. (2002). The relationship between leadership dimensions, cultural beliefs and salutogenic functioning. South African Journal of Labour Relations, 26(1), 65-95.

Luhmann, N. (1984). Soziale Systeme. Grundriss einer allgemeinen Theorie. [Social Systems]. Frankfurt, Germany: Suhrkamp.

Luthans, F., \& Church, A. H. (2002). Positive organizational behavior: Developing and managing psychological strengths. Academy of Management Executive, 16(1), 57-72. doi:10.5465/AME.2002.6640181.

Maak, T., \& Ulrich, P. (2007). Integre Unternehmensführung: Ethisches Orientierungswissen für die Wirtschaftspraxis. Stuttgart: Schäffer-Poeschel.

Nelson, D. L., \& Cooper, C. L. (2008). Positive organizational behavior: An inclusive view. In D. L. Nelson \& C. L. Cooper (Eds.), Positive organizational behavior. London: Sage.

NHS. (2009). Organisational health: A new perspective on performance improvement? Coventry, UK: NHS.

Nielsen, K., Abildgaard, J. S., \& Daniels, K. (2014). Putting context into organizational intervention design: Using tailored questionnaires to measure initiatives for worker well-being. Human Relations, 67(12), 1537-1560. doi:10.1177/0018726714525974.

Nielsen, K., Stage, M., Abildgaard, J. S., \& Brauer, C. V. (2013). Participatory intervention from an organizational perspective: Employees as active agents in creating a healthy work environment. In G. F. Bauer \& G. J. Jenny (Eds.), Salutogenic organizations and change (pp. 327-350). Dordrecht, The Netherlands: Springer. doi:10.1007/978-94-007-6470-5_18.

Peiró, J. M. (2000). Assessment of psychosocial risks and prevention strategies: The amigo model as the basis of the prevenlab/ psicosocial methodology. Psychology in Spain, 4(1), 139-166. Retrieved from http://dialnet.unirioja.es/servlet/articulo? codigo $=960634 \&$ info $=$ resumen $\&$ idioma $=$ ENG.

Peiró, J. M., \& Rodríguez, I. (2008). Work stress, leadership and organizational health. Papeles Del Psicologo, 29(1), 68-81.

Quick, J. C., Macik-Frey, M., \& Cooper, C. L. (2007). Managerial dimensions of organizational health: The healthy leader at work. Journal of Management Studies, 44(2), 189-205. Retrieved from http://dx.doi.org/10.1111/j.1467-6486.2007.00684.x.

Randall, R., Griffiths, A., \& Cox, T. (2005). Evaluating organizational stress-management interventions using adapted study designs.
European Journal of Work and Organizational Psychology, 14(1), 23-41.

Randall, R., \& Nielsen, K. (2012). Does the intervention fit? An explanatory model of intervention success and failure in complex organizational environments. In C. Biron, M. Karanika-Murray, \& C. L. Cooper (Eds.), Improving organizational interventions for stress and ... (pp. 120-135). East Sussex: Routledge.

Rüegg-Stürm, J. (2003). Das Neue St. Galler Management-Modell: Grundkategorien einer integrierten Managementlehre. Der HSG-Ansatz [The New Management Model of St. Gallen: Basic dimensions for integrated management studies. The $H S G$-approach] (2nd ed.). Bern, Switzerland: Paul Haupt.

Salanova, M., Llorens, S., Cifre, E., \& Martinez, I. M. (2012). We need a hero! Toward a validation of the healthy and resilient organization (HERO) model. Group \& Organization Management, 37(6), 785-822. doi:10.1177/1059601112470405.

Seligman, M. E. P., \& Csikszentmihalyi, M. (2000). Positive psychology-An introduction. American Psychologist, 55(1), 5-14. doi:10. 1037//0003-066x.55.1.5.

Shoaf, C., Genaidy, A., Karwowski, W., \& Huang, S. H. (2004). Improving performance and quality of working life: A model for organizational health assessment in emerging enterprises. Human Factors and Ergonomics in Manufacturing, 14(1), 81-95. doi:10. 1002/hfm.10053.

Vogt, K., Jenny, G. J., \& Bauer, G. F. (2013). Comprehensibility, manageability and meaningfulness at work: Construct validity of a scale measuring work related sense of coherence. SA Journal of Industrial Psychology, 39(1), 1-8. doi:10.4102/sajip.v39i1.1111.

von Thiele Schwarz, U., \& Hasson, H. (2013). Alignment for achieving a healthy organization. In G. F. Bauer \& G. J. Jenny (Eds.), Salutogenic organizations and change: The concepts behind organizational health intervention research (pp. 107-125). Dordrecht: Springer. doi:10.1007/978-94-007-6470-5_7.

WHO. (1986). Ottawa charter for health promotion. Geneva: World Health Organization. Retrieved from http://www.who.int/ healthpromotion/conferences/previous/ottawa/en/.

WHO. (1998). Health promotion glossary. Geneva: WHO.

WHO. (2010). WHO healthy workplace framework and model: Background and supporting literature and practice. Geneva: WHO. Retrieved from http://www.who.int/occupational_health/healthy_ workplace_framework.pdf.

Zwetsloot, G., Leka, S., \& Jain, A. (2008). Corporate social responsibility \& psychosocial risk management. In S. Leka \& T. Cox (Eds.), The European framework for psychosocial risk management: PRIMA-EF (pp. 96-114). Nottingham: I-WHO. 